JAMP: Jurnal Adminitrasi dan Manajemen Pendidikan

Volume 3 Nomor 3 September 2020, Hal : 233-238

Tersedia Online di http://journal2.um.ac.id/index.php/jamp/

ISSN 2615-8574 (online)

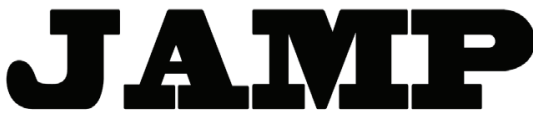

JURNAL ADMINISTRASI DAN MANAJEMEN PENDIDIKAN

\title{
PERBEDAAN TINGKAT KINERJA PEGAWAI TATA USAHA DITINJAU DARI JENIS KELAMIN DI PERGURUAN TINGGI
}

\author{
Nova Syafira Ariyanti \\ Bambang Budi Wiyono \\ Agus Timan \\ Burhanuddin \\ Mustiningsih
Manajemen Pendidikan, Fakultas Ilmu Pendidikan, Universitas Negeri Malang
Jalan Semarang No. 5 Malang, Jawa Timur, Indonesia
e-mail: novasyafira2@gmail.com

\begin{abstract}
The aim of this research is, (1) to know the level of employee performance based on male gender, (2) to know the level of employee performance based on female gender, and (3) to know whether or not the performance difference is based on the gender of the employee. This research is a comparative descriptive research. The sampling techniques used in each unit in Universitas Negeri Malang (UM) used proportional random sampling with a sample number of 301 employees. The analytical techniques used in this research are descriptive analysis and independent sample T-Test with the help of SPSS 24.0 program. The results of this research are; (1) UM employee performance level based on male gender is in excellent category, (2) UM employee performance based on female gender are in excellent category, and (3) There is no difference in performance based on the gender of the UM officers.
\end{abstract}

Keywords: employee performance, gender, higher education

\begin{abstract}
Abstrak: Tujuan penelitian ini yakni, (1) mengetahui tingkat kinerja pegawai berdasarkan jenis kelamin laki-laki, (2) mengetahui tingkat kinerja pegawai berdasarkan jenis kelamin perempuan, dan (3) mengetahui ada atau tidaknya perbedaan kinerja berdasarkan jenis kelamin pegawai. Penelitian ini merupakan penelitian deskriptif komparatif. Teknik pengambilan sampel yang digunakan di masing-masing unit di lingkungan Universitas Negeri Malang (UM) menggunakan proportional random sampling dengan jumlah sampel sebanyak 301 orang pegawai. Teknik analisis yang digunakan dalam penelitian ini yakni analisis deskriptif dan independent sample t-test dengan bantuan program SPSS 24.0. Hasil penelitian ini yakni; (1) tingkat kinerja pegawai UM berdasarkan jenis kelamin laki-laki berada pada kategori sangat baik, (2) tingkat kinerja pegawai UM berdasarkan jenis kelamin perempuan berada pada kategori sangat baik, dan (3) tidak ada perbedaan kinerja berdasarkan jenis kelamin pegawai UM.
\end{abstract}

Kata Kunci: kinerja pegawai, jenis kelamin, perguruan tinggi

Organisasi pendidikan memiliki banyak unsur dalam proses pelaksanaan kegiatannya. Hal ini menunjukkan dalam proses pelaksanaan tersebut terdapat beberapa sumber daya. Salah satunya yakni, sumber daya manusia yang merupakan faktor utama dalam melaksanakan proses manajemen yang ada dalam suatu organisasi. Dalam sumber daya manusia pun terdapat beberapa proses seperti rekrutmen, orientasi, pembinaan, pengembangan karir, pemberdayaan, sampai dengan Pemutusan Hubungan Kerja (PHK). Proses-proses tersebut dapat mengoptimalkan sumber daya manusia yang ada dalam organisasi. Pentingnya sumber daya manusia menurut Cobanoglu et al. (2018) yakni untuk menentukan strategi dalam meningkatkan dan mempertahankan kinerja pegawai. hal ini mengharuskan setiap organisasi 
untuk memperhatikan sumber daya manusia. Oleh karenanya, dalam proses tersebut dibutuhkan pengoptimalan sumber daya manusia agar tercapai tujuan yang telah ditetapkan.

Seperti pada pendidikan tinggi yang merupakan organisasi dalam skala besar, tentunya hal ini menjadikan dalam prosesnya juga berinteraksi dengan banyak kalangan. Dengan begitu, pengoptimalan sumber daya manusia di tingkat perguruan tinggi perlu diperhatikan. Sama halnya dengan Universitas Negeri Malang (UM) yang melayani banyak pihak seperti mahasiswa, dosen dan stakeholder (Adha et al., 2018). Pegawai UM juga harus memperhatikan kinerjanya melalui beberapa unsur yang ada. Salah satunya, untuk membangun citra positif perguruan tinggi kepada masyarakat, dapat menerapkan manajemen sumber daya manusia melalui kinerja pegawai (Öztürk, 2016). Maknanya, untuk meningkatkan dan mempertahankan kinerja pegawai dapat melalui sumber daya manusia, hal ini dapat dilakukan untuk mencapai tujuan perguruan tinggi. Potensi yang dimiliki oleh pegawai dapat dilihat berdasarkan kinerja pegawai.

Perkembangan pendidikan pada era revolusi industri 4.0 secara langsung berdampak pada pendidikan yakni dengan beberapa perubahan dalam metode pengajaran. Perubahan metode pembelajaran menuntut para tenaga kependidikan atau pegawai untuk mengikuti perubahan yang ada. Secara langsung pula tenaga kependidikan yang ada harus bisa menunjukkan skill atau kemampuan dalam bidangnya. Dengan begitu perubahan pada abad ke 21 ini menuntut tenaga kependidikan untuk mengikuti perubahan yang ada. Hal ini dapat ditunjukkan dengan kinerja pegawai. Menurut Sedarmayanti (2011) kinerja dalam Bahasa inggris yakni performance yang memiliki makna hasil kerja, hasil kerja ini dapat ditunjukkan melalui proses manajemen di dalam organisasi atau lembaga dengan membandingkan pada standar yang ditentukan atau dijadikan patokan dalam organisasi.

Kinerja pegawai dapat dilihat berdasarkan kebiasaan yang dilakukan oleh pegawai ketika bekerja. Menurut Pradhan \& Jena (2017) kinerja merupakan pemanfaatkan dari sumber daya manusia untuk mencapai keberhasilan yang telah ditetapkan organisasi. Tidak hanya itu, kinerja juga dapat menyelaraskan keadaan organisasi dengan kebijakan yang ada sehingga dalam prosesnya dapat mendorong kegiatan organisasi mejadi lebih strategis. Demikian juga dengan pendapat Sendawula et al. (2018) menyatakan bahwa kinerja pegawai merupakan aset yang penting dalam meningkatkan reputasi dari sebuah organisasi. Maknanya, organisasi ketika ingin meningkatkan kualitas agar lebih dikenal oleh masyarakat bisa melalui kinerja pegawai. Hal ini dapat dilakukan melalui pembinaan dan pemberdayaan pegawai dalam manajemen sumber daya manusia. Untuk pembinaan dan pemberdayaan pegawai sendiri biasanya terdapat kesamaan dalam memberikan treatment kepada pegawai laki-laki dan perempuan.

Peran jenis kelamin melalui berbagai sistem biasanya sama, hal ini menjadikan peran dari pegawai laki-laki dan perempuan menurut kondisinya memiliki kesamaan. Tidak jarang melihat pekerjaan laki-laki yang dikerjakan oleh perempuan, begitu pula sebaliknya. Terdapat beberapa indikator dalam melihat kinerja pegawai berdasarkan jenis kelamin ini sama atau berbeda. Pendapat Lasut et al. (2017) menyatakan bahwa peran jenis kelamin dalam kinerja pegawai tidak terdapat perbedaan. Maknanya, dalam melakukan dan menyelesaikan pekerjaan untuk laki-laki dan perempuan terdapat kesamaan dari segi kualitas dan kuantitas.

\section{METODE}

Penelitian ini menggunakan pendekatan kuantitatif. Penelitian kuantitatif dimaksudkan untuk mendeskripsikan suatu fenomena sebagaimana adanya pada waktu penelitian dilakukan (Wiyono, 2007). Penelitian ini didasarkan pada teori yang ditemukan oleh peneliti kemudian dikembangkan menjadi sebuah permasalahan yang ada di lapangan, selanjutnya dilakukan penelitian untuk menemukan suatu kebenaran dari teori dan keadaan sebenarnya di lapangan. Jenis penelitian yang digunakan adalah expost facto artinya sesudah fakta, penelitian yang dilakukan setelah suatu kejadian terjadi. Penelitian ini bersifat deskriptif karena bertujuan mendapatkan gambaran tentang variabel yang diteliti.

Populasi penelitian ini yakni Pegawai Universitas Negeri Malang (UM). Jumlah populasi dalam penelitian ini sebanyak 1053 orang. Teknik pengambilan sampel yang digunakan di masing-masing 
unit menggunakan proportional random sampling. Hal ini dikarenakan, penulis menggunakan teknik kelipatan 3 di setiap unit. Menggunakan rumus Slovin didapatkan sampel secara keseluruhan dalam penelitian ini sebanyak 301 orang responden. Pada penelitian ini menggunakan angket tertutup. Menurut Wiyono (2007) kuesioner tertutup merupakan suatu kuesioner yang diberikan kepada responden dengan menyediakan pilihan jawaban lengkap dan responden tinggal memberi tanda pada jawaban yang dipilih.

Instrumen yang baik harus valid serta reliabel. Tingkat validitas butir pernyataan instrumen digunakan teknik korelasi product moment pearson menggunakan bantuan program SPSS 24.0. Kriteria butir pernyataan dinyatakan valid apabila nilai signifikansi $<0,300$. Berdasarkan hasil uji validitas dinyatakan semua item pernyataan dinyatakan valid, selanjutnya dilakukan uji reliabilitas. Uji reliabilitas dilakukan menggunakan cronbach's alpha dengan bantuan program SPSS 24.0, dimana instrumen dinyatakan reliabel bila nilai cronbach's alpha $>0,600$ (Arikunto, 2010). Analisis data yang digunakan dalam penelitian ini ialah analisis deskriptif dan Independent Samples T Test, uji ini dilakukan untuk mengetahui ada atau tidaknya perbedaan rata-rata antara dua kelompok sampel yang tidak berpasangan. Penelitian ini dalam melakukan analisis data menggunakan bantuan Statistical Package for Social Science for windows versi 24.0.

\section{HASIL}

\section{Deskripsi Data Kinerja Pegawai Laki-Laki}

Deskripsi data untuk kinerja pegawai laki-laki sebanyak 189 responden. Berdasarkan Tabel 1 menunjukkan bahwa kinerja pegawai laki-laki diperoleh kriteria sangat baik dengan persentase sebanyak $49,73 \%$, baik sebanyak $48,68 \%$, kurang baik sebanyak $1,59 \%$ dan untuk kriteria tidak baik tidak ada. Berdasarkan analisis data tersebut bahwa persentase tingkat kinerja pegawai laki-laki di lingkungan UM berada pada kriteria sangat baik yakni sebesar $49,73 \%$. Hal ini menunjukkan bahwa kinerja pegawai dapat dipertahankan agar tetap mencapai kriteria sangat baik.

Tabel 1. Deskripsi Data Kinerja Pegawai Laki-Laki

\begin{tabular}{ccccc}
\hline No. & Kategori & Interval & Frekuensi & Persentase \\
\hline 1 & Sangat Baik & $116-142$ & 94 & $49,73 \%$ \\
2 & Baik & $89-115$ & 92 & $48,68 \%$ \\
3 & Kurang Baik & $62-88$ & 3 & $1,59 \%$ \\
4 & Tidak Baik & $35-61$ & 0 & $0,00 \%$ \\
& Jumlah & & $\mathbf{1 8 9}$ & $\mathbf{1 0 0 , 0 0 \%}$ \\
\hline
\end{tabular}

Adapun diagram hasil distribusi persentase kinerja pegawai laki-laki dapat dilihat pada Gambar 1.

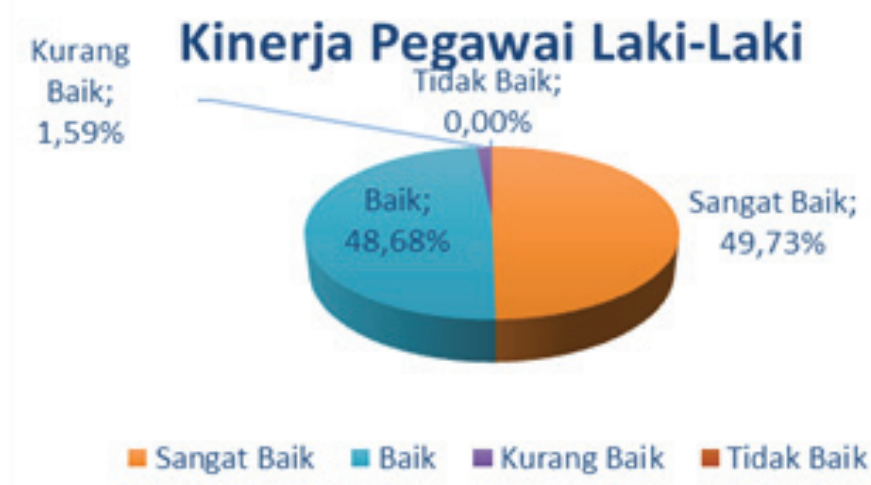

Gambar 1. Distribusi Persentase Variabel Kinerja Pegawai Laki-Laki 


\section{Distribusi data kinerja pegawai perempuan}

Deskripsi data untuk kinerja pegawai perempuan sebanyak 110 responden. Berdasarkan Tabel 2 menunjukkan bahwa kinerja pegawai laki-laki diperoleh kriteria sangat baik dengan persentase sebanyak $48,18 \%$, baik sebanyak $45,46 \%$, kurang baik sebanyak $6,36 \%$ dan untuk kriteria tidak baik tidak ada. Berdasarkan analisis data tersebut bahwa persentase tingkat kinerja pegawai perempuan di lingkungan UM berada pada kriteria sangat baik yakni sebesar $45,18 \%$. Hal ini menunjukkan bahwa kinerja pegawai dapat dipertahankan agar tetap mencapai kriteria sangat baik.

Tabel 2. Distribusi Data Kinerja Pegawai Perempuan

\begin{tabular}{ccccc}
\hline No. & Kategori & Interval & Frekuensi & Persentase \\
\hline 1 & Sangat Baik & $116-142$ & 53 & $48,18 \%$ \\
2 & Baik & $89-115$ & 50 & $45,46 \%$ \\
3 & Kurang Baik & $62-88$ & 7 & $6,36 \%$ \\
4 & Tidak Baik & $35-61$ & 0 & $0,00 \%$ \\
& Jumlah & & $\mathbf{1 1 0}$ & $\mathbf{1 0 0 , 0 0 \%}$ \\
\hline
\end{tabular}

Adapun diagram hasil distribusi persentase kinerja pegawai perempuan dapat dilihat pada Gambar 2.

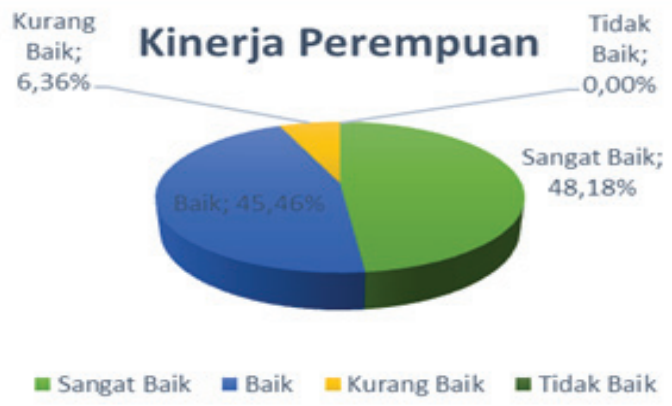

Gambar 2. Distribusi Persentase Kinerja Pegawai Perempuan

\section{Uji Asumsi}

Uji asumsi data dalam penelitian ini memerlukan uji normalitas dan uji homogenitas. Untuk mengetahui data dalam penelitian normal atau tidak, dapat dilakukan uji normalitas. Uji normalitas merupakan salah satu syarat untuk analisis parametrik, sebab dalam uji parametrik, data harus berdistribusi normal. Uji normalitas dalam penelitian ini menggunakan analisis Kolgomorov Smirnov Test dengan bantuan SPSS 24.0, dengan kriteria apabila nilai asymp. Sig > 0,05, maka data dapat dinyatakan berdistribusi normal. Hasil uji normalitas dapat dilihat pada Tabel 3.

Tabel 3. Hasil Uji Normalitas Data

\begin{tabular}{llrr}
\hline & One-Sample Kolmogorov-Smirnov Test & \\
Kinerja Laki-Laki & Kinerja Perempuan \\
\hline $\mathrm{N}$ & & 191 & 110 \\
Normal Parameters ${ }^{\mathrm{a}, \mathrm{b}}$ & & 115.44 & 114.32 \\
& Mean & 13.690 & 14.003 \\
Most Extreme Differences & Std. Deviation & & 0.073 \\
Absolute & & & \\
& & 0.047 & \\
& & 0.036 & 0.036 \\
& Positive & -0.047 & -0.073 \\
& Negative & 0.047 & 0.073 \\
Test Statistic & & 0.200 & 0.194 \\
Asymp. Sig. (2-tailed) & &
\end{tabular}


Uji normalitas data dilakukan untuk mengetahui normal atau tidaknya data minat berwirausaha berdasarkan jenis kelamin mahasiswa. Berdasarkan Tabel 3 uji normalitas One-Sample KolgomorovSmirnov Test menghasilkan nilai asymp. Sig. secara berturut-turut yakni sebesar 0,200 dan 0,194. Berdasarkan hasil tersebut diketahui nilai asymp. Sig. data kinerja pegawai berdasarkan jenis kelamin pegawai diperoleh nilai lebih besar dari $(>0,05)$, karena nilai signifikansi lebih besar dari $(>0,05)$ maka data dapat dinyatakan berdistribusi normal.

Tahap berikutnya dalam uji asumsi dalam penelitian ini adalah melakukan uji homogenitas. Salah satu syarat untuk mendapatkan hasil uji beda yang akurat yakni data yang diasumsikan homogen. Uji homogenitas dilakukan dengan levene's test dan didapatkan nilai signifikansi sebesar 0,677. Berdasarkan nilai signifikansi yang lebih besar dari $(>0,05)$, maka data dapat dinyatakan homogen. Hasil uji homogenitas data dapat dilihat pada Tabel 4.

\section{Tabel 4. Hasil Uji Homogenitas Data}

\begin{tabular}{cccc}
\hline \multicolumn{4}{c}{ Test of Homogeneity of Variances } \\
Kinerja Pegawai \\
\hline Levene Statistic
\end{tabular}

\section{Uji Hipotesis}

Pengujian perbedaan kinerja pegawai berdasarkan jenis kelamin dilakukan menggunakan Independent Samples T Test, uji ini dilakukan untuk mengetahui ada atau tidaknya perbedaan rata-rata antara dua kelompok sampel yang tidak berpasangan. Hasil pengujian hipotesis dapat dilihat pada Tabel 5, dengan hipotesis sebagai berikut:

H0: tidak ada perbedaan tingkat kinerja berdasarkan jenis kelamin pegawai

Ha: ada perbedaan tingkat kinerja berdasarkan jenis kelamin pegawai

Tabel 5. Hasil Uji Hipotesis

\begin{tabular}{llcccc}
\hline Kelompok & Mean & t-hit & Sig. & Cut of value & Keputusan \\
\hline Laki-laki & 115,44 & & & & \\
Perempuan & 114,32 & 0,679 & 0,498 & 0,050 & H0 diterima \\
\hline
\end{tabular}

Kriteria pengujian hipotesis apabila nilai sig. $<0,050$, maka H0 ditolak. Berdasarkan Tabel 5 dapat diketahui nilai sig. ditemukan sebesar 0,498 , artinya nilai sig, lebih besar dari $(>0,05)$, maka $\mathrm{H} 0$ diterima dan Ha ditolak. Dengan demikian dapat dinyatakan tidak ada perbedaan yang signifikan antara tingkat kinerja pegawai berjenis kelamin laki-laki dan perempuan.

\section{PEMBAHASAN}

Perbedaan tingkat kinerja berdasarkan jenis kelamin pegawai di UM menunjukkan bahwa tidak terdapat perbedaan diantara keduanya. Hal menunjukkan bahwa kinerja pegawai laki-laki dan perempuan sama. Sama halnya dengan pendapat Ayu (2015) menyatakan bahwa kinerja dari pegawai laki-laki dan perempuan tidak berbeda. Maknanya, dalam proses menyelesaikan pekerjaan terdapat kesamaan walaupun dengan gender yang berbeda.

Pendapat Ethington (2019) menyatakan bahwa pegawai berjenis kelamin laki-laki dan perempuan dalam proses melakukan pekerjaan tidak terdapat pekerjaan. Sehingga, hal ini menjadikan hasil pekerjaan pegawai dengan jenis kelamin laki-laki dan perempuan mempunyai kesamaan. Dalam hal lain, terdapat penjelasan bahwa pegawai dengan jenis kelamin berbeda biasanya cenderung berbeda dalam menyelesaikan pekerjaan, tetapi dalam hal ini untuk pegawai dengan jenis kelamin berbeda dapat menyelesaikan pekerjaan yang sama. 
Beberapa indikator kinerja pegawai menurut Robbins (1996) menjelaskan bahwa terdapat efektivitas biaya dalam penyelesaiannya. Untuk efektivitas biaya sendiri terdapat beberapa unsur yakni sumber daya manusia, pengelolaan keuangan berdasarkan hasil kerja, cara dalam bekerja, dan peralatan penunjang pekerjaan. Dapat dilihat berdasarkan sumber daya manusia dalam menyelesaikan pekerjaan, untuk sumber daya manusia ini termasuk jenis kelamin. Sehingga, dalam penyelesaian pekerjaan ini dapat dinilai seberapa efektif kinerja pegawai laki-laki dan perempuan.

\section{SIMPULAN DAN SARAN}

\section{Simpulan}

Berdasarkan hasil dan penelitian, simpulan dalam penelitian ini adalah (1) tingkat kinerja pegawai UM dengan jenis kelamin laki-laki berada pada kategori sangat baik, (2) tingkat kinerja pegawai UM dengan jenis kelamin perempuan berada pada kategori sangat baik, dan (3) tidak ada perbedaan kinerja berdasarkan jenis kelamin pegawai, melalui kualitas, kuantitas, efektivitas, ketepatan waktu dan kemandirian diharapkan seluruh pegawai memiliki kemampuan dalam menyelesaikan pekerjaan yang sama baiknya. Melalui pengetahuan dan keterampilan dalam memahami pekerjaan ke depannya dapat mempertahankan kinerja yang sangat baik.

\section{Saran}

Berdasarkan simpulan yang telah dipaparkan, maka penulis memberikan saran kepada beberapa pihak yakni, (1) Rektor UM, meningkatkan kinerja pegawai melalui evaluasi pekerjaan yang telah dilakukan pegawai, (2) Dekan, Kepala UPT dan Ketua Lembaga, untuk meningkatkan pengawasan kinerja pegawai agar tetap dalam kategori sangat baik, (3) Kepala Tata Usaha Fakultas, UPT dan Lembaga, mempertahankan kinerja pegawai yang sudah baik, (4) Pegawai UM, tetap memberikan kinerja yang prima, dan (5) Peneliti lain, dapat melanjutkan penelitian yang relevan mengenai indikator lain seperti pendidikan terakhir, usia, dan masa kerja.

\section{DAFTAR PUSTAKA}

Adha, M. A., Mustiningsih, M., \& Maisyaroh, M. (2018). Hubungan Pelaksanaan Sistem Informasi Manajemen Berbasis Komputer Dan Keefektifan Kinerja Pns Di Perguruan Tinggi. Jurnal Administrasi Dan Manajemen Pendidikan, 1(2), 124-131. http://journal2.um.ac.id/index.php/jamp/article/view/2663/1815

Arikunto, S. (2010). Prosedur Penelitian: Suatu Pendekatan Praktik. Bumi Aksara.

Ayu, M. I. (2015). Pengaruh Gender Dan Stres Kerja Terhadap Kinerja Karyawan Pada PT. Paragon Technology And Innovation Bandung. Repository Scholar Unikom.

Cobanoglu, F., Sertel, G., \& Sarkaya, S. S. (2018). Human resource management practices in Turkish education system (Denizli case). European Journal of Educational Research, 7(4), 833-847. https://doi.org/10.12973/ eu-jer.7.4.833

Ethington, C. A. (2019). Gender Differences in Mathematics: An International Perspective. Journal for Research in Mathematics Education, 22(1), 74. https://doi.org/10.2307/749458

Lasut, E. E., Lengkong, V. P. K., \& Ogi, I. W. J. (2017). Analisis Perbedaan Kinerja Pegawai Berdasarkan Gender, Usia Dan Masa Kerja (Studi Pada Dinas Pendidikan Sitaro). Jurnal EMBA: Jurnal Riset Ekonomi, Manajemen, Bisnis Dan Akuntansi, 5(3), 2771-2780. https://doi.org/10.35794/emba.v5i3.17155

Öztürk, S. (2016). Human resources management in educational faculties of state universities in turkey. International Journal of Environmental and Science Education, 11(5), 931-948. https://doi.org/10.12973/ijese.2016.503a

Pradhan, R. K., \& Jena, L. K. (2017). Employee Performance at Workplace: Conceptual Model and Empirical Validation. Business Perspectives and Research, 5(1), 69-85. https://doi.org/10.1177/2278533716671630

Robbins, S. P. (1996). Organizational Behavior. Prentice Hall.Inc.

Sedarmayanti. (2011). Manajemen Sumber Daya Manusia. Mandar Maju.

Sendawula, K., Nakyejwe Kimuli, S., Bananuka, J., \& Najjemba Muganga, G. (2018). Training, employee engagement and employee performance: Evidence from Uganda's health sector. Cogent Business and Management, 5(1), 1-12. https://doi.org/10.1080/23311975.2018.1470891

Wiyono, B. B. (2007). Metodologi Penelitian (Pendekatan Kuantitatif, Kualitatif, dan Action Research (Burhanuddin (ed.)). Universitas Negeri Malang. 